\title{
Rapid Solid-State Metathesis Route to Transition-Metal Doped Titanias
}

\author{
Nathaniel Coleman, Jr., Sujith Perera, Edward G. Gillan \\ Department of Chemistry, University of Iowa, Iowa City, Iowa 52242 \\ Corresponding Author Email: edward-gillan@uiowa.edu
}

\begin{abstract}
Rapid solid-state metathesis (SSM) reactions are often short-lived highly exothermic reactions that yield a molten alkali halide salt that aids in product growth and crystallization. SSM reactions may also produce kinetically stabilized structures due to the short (seconds) reaction times. This report describes the investigation of rapid SSM reactions in the synthesis of transition-metal doped titanias $\left(\mathrm{M}-\mathrm{TiO}_{2}\right)$. The dopant targeted compositions were ten mol percent and based on elemental analysis, many of the ${\mathrm{M}-\mathrm{TiO}_{2}}_{2}$ samples were close to this targeted level. Based on surface analysis, some samples showed large enrichment in surface dopant content, particularly chromium and manganese doped samples. Due to the highly exothermic nature of these reactions, rutile structured $\mathrm{TiO}_{2}$ was observed in all cases. The $\mathrm{M}-\mathrm{TiO}_{2}$ samples are visible colored and show magnetic and optical properties consistent with the dopant in an oxide environment. UV and visible photocatalytic experiments with these visibly colored rutile $\mathrm{M}-\mathrm{TiO}_{2}$ powders showed that many of them are strongly absorbent for methylene blue dye and degrade the dye under both UV and visible light illumination. This work may open up SSM reactions as an alternate nonthermodynamic reaction strategy for dopant incorporation into a wide range of oxide and non-oxides.
\end{abstract}

Keywords: metathesis, metal doping, titania, photocatalysis 


\section{Introduction}

Metal oxide coatings and particles have been utilized in a wide range of materials applications including energy storage and catalysis for energy or fuel production. In the photocatalytic arena, titanium dioxide (titania or $\mathrm{TiO}_{2}$ ) is an extensively studied UV absorbing oxide with utility in both organic dye photocatalytic oxidation and water splitting reactions. $\mathrm{TiO}_{2}$ photocatalysis has been utilized for selfcleaning window coatings. ${ }^{1-2}$ Titania exists in primarily two synthetically accessible forms with UV band gap $\left(E_{g}\right)$ energies: anatase $\left(E_{g}=3.2 \mathrm{eV}\right)$ and rutile $\left(E_{g}=3.0 \mathrm{eV}\right)$. Typical solution precursor condensation routes to $\mathrm{TiO}_{2}$ involve heating amorphous titanium hydroxide precipitates near $\sim 500{ }^{\circ} \mathrm{C}$ to produce the more catalytically active anatase form. Anatase irreversibly transforms to the thermodynamically stable rutile form upon heating to higher temperatures near $600{ }^{\circ} \mathrm{C}$, with the transition temperature influenced by precursor used and presence of trace impurities or dopants in the amorphous structure. ${ }^{3}$ While bulk crystalline rutile $\mathrm{TiO}_{2}$ is less UV photocatalytically active than anatase, likely due to recombination of photogenerated electrons and holes, rutile nanoparticles have shown significant photo-assisted oxidation properties. ${ }^{4}$ Commercial $\mathrm{TiO}_{2}$ that is a mixture of anatase: rutile in $~ 4: 1$ ratio (e.g., Degussa P25) shows notably high photocatalytic activity. The nature of this activity is appears to be synergistic electronic effects between anatase and rutile particles. ${ }^{5}$

In addition to being composed of earth-abundant low toxicity elements, $\mathrm{TiO}_{2}$ shows high UV photocatalytic activity and chemical stability in acidic and basic environments. Renewed interest in $\mathrm{TiO}_{2}$ photoactivity stems from its ability to produce hydrogen gas fuel from renewable resources, particularly by providing photogenerated electrons to a platinum co-catalyst that produces $\mathrm{H}_{2}$ from water under UV illumination. ${ }^{6}$ Both gold and platinum metal particles deposited on titania show photocatalytic utility. ${ }^{7-8}$ Synthetic efforts in recent years have focused on modifying titania light absorption properties into the desirable visible light solar spectrum. For example, organic dyes placed on its surface allow anatase titania nanoparticles to act as photovoltaic light to energy conversion (solar cell) materials. ${ }^{9}$

Alternate methods to improve titania visible light absorption take advantage of metal and non-metal dopant incorporation into the titania structure. The dopant species can either substitute for $\mathrm{Ti}$ or $\mathrm{O}$ ions in the lattice or to occupy interstitial sites in the structure or form oxyanions embedded in the lattice. Anion doping by main-group elements (e.g., C, N, S, halogens) ${ }^{10}$ onto the oxygen site or into interstitials can potentially raise valence band or lower the conduction band energy levels or introduce new dopant levels within the band gap for visible light absorption. ${ }^{11-16}$ Ionic radii of many common oxidation states of transition metal of $\sim 70-90 \mathrm{pm}$ are similar to the $\mathrm{Ti}^{4+}$ ionic radius or $75 \mathrm{pm} .{ }^{17}$ Cation doping of titania with transition-metal and main-group metals includes $\mathrm{Fe},{ }^{18-19} \mathrm{Co},{ }^{20} \mathrm{Cr},{ }^{21} \mathrm{Ni},{ }^{22}$ and $\mathrm{Mn}$, often leading to 
colored titanias. ${ }^{23-24}$ Most titania doping methods begin with solution reaction/precipitation or ionimplantation followed by thermal annealing or crystallization. Typically, dopant additions to $\mathrm{TiO}_{2}$ are at low $1-5 \%$ levels to limit thermodynamically preferred second phases that will form during high temperature annealing. While transition-metal dopants may impart visible light absorption properties to $\mathrm{TiO}_{2}$, such dopants may also act as recombination centers for photogenerated electron and holes. ${ }^{25-26}$ Apart from photocatalytic activity, transition-metal doped $\mathrm{TiO}_{2}$ can also exhibit interesting dilute magnetic semiconductor (DMS) properties when doped with magnetic ions. ${ }^{27-29}$ Metal doped titanias have also found application in hydrogen evolution catalysis and lithium ion batteries. ${ }^{30-32}$

This paper describes a solvent-free single-step reaction to rapidly produce metal-doped titanias using a solid state metathesis (SSM) reaction strategy that takes advantage of precursor thermochemical exothermicity to produce crystalline products in seconds in self-propagating reactions that often require little or no external energy input. Rapid SSM reactions are an alternate strategy to solution phase reactions and can rapidly produce crystalline metal oxide and non-oxide materials using highly exothermic ion exchange reactions without the need for subsequent annealing. The SSM reactions extend back to the early 1900's, but were actively developed as a rapid materials growth strategy over the past couple of decades. Work in the early 1990's by Kaner and Parkin demonstrated the utility of rapid selfpropagating SSM reactions to produce a wide range of inorganic materials in seconds using initiation methods including hot wires, ampoules placed in heated furnaces, and by external flames. ${ }^{33-35}$ Crystalline products rapidly formed by SSM reactions include layered $\mathrm{MX}_{2}(\mathrm{M}=\mathrm{Mo}, \mathrm{W}, \mathrm{X}=\mathrm{S}, \mathrm{Se}),{ }^{36} \mathrm{GaE}(\mathrm{E}=\mathrm{N}, \mathrm{P}$, As), ${ }^{37-38}$ transition-metal and lanthanide nitrides, phosphides, and borides (e.g, ZrN, GdN, ZrP, and $\left.\mathrm{TiB}_{2}\right){ }^{39-42}$

Relevant to the current work, solid-state oxygen source reagents (e.g., $\mathrm{Na}_{2} \mathrm{O}, \mathrm{Na}_{2} \mathrm{O}_{2}, \mathrm{Li}_{2} \mathrm{O}$ ) have been used for SSM growth of transition-metal oxides, including complex $\mathrm{AM}_{\mathrm{x}} \mathrm{O}_{\mathrm{y}}$ structures. $^{33,43-45}$ A rapid SSM reaction was also utilized to produce cubic stabilized $\mathrm{ZrO}_{2}$ by doping zirconia with $\mathrm{Ca}$, Y, or Ce ( 5-10\%) during the SSM process. ${ }^{46}$

In previous work, we produced crystalline rutile $\mathrm{TiO}_{2}$ microparticles using a rapid and exothermic SSM reaction between $\mathrm{TiCl}_{3}$ and $\mathrm{Na}_{2} \mathrm{O}_{2}$ (Equation 1$){ }^{47}$

$$
\mathrm{TiCl}_{3}+1.5 \mathrm{Na}_{2} \mathrm{O}_{2} \rightarrow \mathrm{TiO}_{2}+3 \mathrm{NaCl}+0.5 \mathrm{O}_{2}
$$

Rutile $\mathrm{TiO}_{2}$ is synthesized in seconds using this exothermic exchange reaction that transiently reaches temperatures as high as the $\mathrm{NaCl}$ boiling point of $\sim 1400^{\circ} \mathrm{C}$. We also synthesized anatase $\mathrm{TiO}_{2}$ nanoparticles using similar exchange reactions under solvothermally heated conditions. ${ }^{48}$ In the current 
study, we examine the ability of rapid SSM reactions to introduce moderate ( 10 at\%) levels of transition-metals into rutile $\mathrm{TiO}_{2}$. The structural and physical properties of these SSM-synthesized metaldoped titanias and their utility in UV and visible organic dye adsorption and oxidation photocatalysis are described.

\section{Experimental Section}

2.1. Reagents. All starting materials were used as received: $\mathrm{TiCl}_{3}$ (Aldrich, $99 \%$ ), $\mathrm{CrCl}_{3}$ (Alfa Aesar, 98\%), $\mathrm{MnCl}_{2}$ (Specialty Inorganics, 99.5\%), $\mathrm{FeCl}_{3}$ (Alfa Aesar, 98\%), $\mathrm{CoCl}_{2}$ (Alfa Aesar, 99.7\%), $\mathrm{NiCl}_{2}$ (Alfa Aesar, 99\%), $\mathrm{CuCl}_{2}$ (Alfa Aesar, 98\%), $\mathrm{Na}_{2} \mathrm{O}_{2}$ (Sigma Aldrich, 97\%). Distilled deionized water (18 $\mathrm{M} \Omega$ ) and $1 \mathrm{M} \mathrm{HCl}$ (Fisher Scientific, diluted) was used for wash processes. P25-TiO 2 (Degussa Corp.) and methylene blue (high purity, Alfa Aesar) or methyl orange (85\% dye content, Sigma Aldrich) dyes were used in photocatalysis studies.

2.2. Synthesis of transition-metal doped $\mathrm{TiO}_{2}$. First-row $3 \mathrm{~d}$ transition metals were incorporated into the $\mathrm{TiO}_{2}$ structure using multiple metal halides precursors in a solid state metathesis (SSM) reaction based on our prior work with $\mathrm{SSM} \mathrm{TiO}_{2}$ synthesis. ${ }^{47}$ All reagent manipulations were performed in a Vacuum Atmospheres argon filled glove box. Each anhydrous metal chloride $\left(\mathrm{MCl}_{2}\right.$ or $\left.\mathrm{MCl}_{3}\right)$ was used in an amount to produce a $1 \mathrm{M}$ to $9 \mathrm{Ti}$ molar ratio for products [e.g., $\mathrm{M}_{0.1} \mathrm{Ti}_{0.9} \mathrm{O}_{2}$ target] or 10 at\% $\mathrm{M}$ with respect to total metal amount. Typically, $2.00 \mathrm{~g}$ (13.0 mmol) of ground $\mathrm{TiCl}_{3}$ was mixed and ground in a mortar and pestle with the dopant metal halide. Specifically, dopant amounts used were: $\mathrm{CrCl}_{3}(0.228 \mathrm{~g}$, $1.44 \mathrm{mmol}$ ), $\mathrm{MnCl}_{2}$ (0.182 g, $1.45 \mathrm{mmol}$ ), $\mathrm{FeCl}_{3}$ (0.236 g, $1.45 \mathrm{mmol}$ ), $\mathrm{CoCl}_{2}$ (0.188 g, 1.45), $\mathrm{NiCl}_{2}$ (0.184 g, $1.42 \mathrm{mmol})$, and $\mathrm{CuCl}_{2}(0.193 \mathrm{~g}, 1.44 \mathrm{mmol})$. The mixed metal halide powder was then mixed with ground $\mathrm{Na}_{2} \mathrm{O}_{2}$ powder. For the $\mathrm{MCl}_{2}$ and $\mathrm{MCl}_{3}$ reactions, respectively, $1.63 \mathrm{~g}$ (20.9 mmol) or $1.69 \mathrm{~g}$ (21.7 mmol) of $\mathrm{Na}_{2} \mathrm{O}_{2}$ was used to properly balance $\mathrm{NaCl}$ salt elimination from the SSM reaction. The intimately ground powders were placed inside a stainless steel crucible that was then placed inside a custom-made thick wall steel SSM ignition reactor that resembles a non-sealed bomb calorimeter (Figure 1). Ceramic and quartz crucibles were initially used for these SSM reactions, however, due to the violent nature or rapid thermal changes that occur in these reactions, such crucibles frequently fractured after only a few uses so a stainless steel crucible was generally used. After placing the steel crucible in the reactor, a $0.64 \mathrm{~mm}$ diameter nichrome wire was attached to two electrical posts on the reactor lid and was buried in the precursor powder. The closed reactor was removed from the glove box and the wire was resistively heated to a red hot level $\left(\sim 500^{\circ} \mathrm{C}\right)$ using a setting of $\sim 10 \mathrm{~V}$ on a Variac, which initiated the SSM reaction. Reaction initiation was observed by wisps of fine powder or smoke exiting the non-sealed edges of the reactor lid and reactions were usually complete within a few seconds leaving the reactor 
exterior walls warm to the touch. The inside of the reactor was usually covered with a thin coating of yellowish, off-white material, and a large amount of a darker glassy product was in the crucible. In order to purify the crude products and remove sodium containing impurities, metal doped titania samples were washed with $100 \mathrm{ml} 1 \mathrm{M} \mathrm{HCl}$ for 30 minutes at room temperature under constant stirring. The acidwashed samples were then rinsed several times with distilled water until the $\mathrm{pH}$ of the rinse was neutral. All solid products were dried in air at room temperature. Selected samples were also annealed for one day at $1000{ }^{\circ} \mathrm{C}$ in air in a box furnace at a heating at a rate of $\sim 100^{\circ} \mathrm{C} / \mathrm{hr}$. The samples were cooled naturally to room temperature.

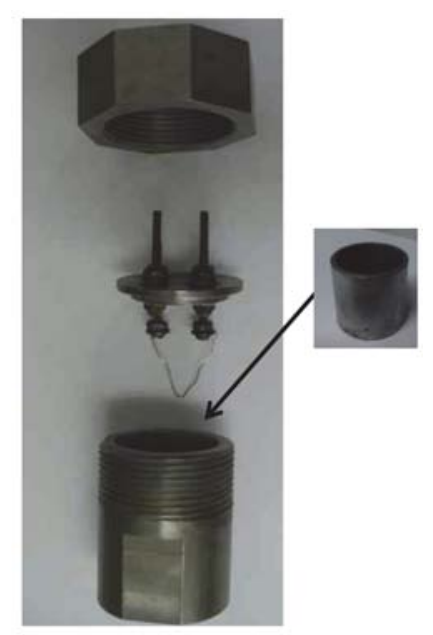

Figure 1. Exploded view image of a home-built steel SSM reactor.

2.3. Product characterization. Phase identification was conducted using Siemens D5000 or Bruker D8 DaVinci powder X-ray diffraction (XRD) systems that analyzed ground powders affixed to glass slides with either vacuum grease or using an acetone slurry. Morphologies and semiquantitative elemental analysis was obtained by scanning electron microscopy (SEM) and energy dispersive spectroscopy (EDS) using a Hitachi S4800 or S3400 system. Samples were ground to fine powders and some were lightly pressed into thin pellets for EDS with an IR pellet hand press then affixed onto aluminum stubs with carbon tape. Samples were carbon coated to minimize charging. Quantitative analysis by ICP-OE spectrometry (Varian 720-ES) was performed on acid dissolved samples. Approximately $5 \mathrm{mg}$ of each sample was dissolved in an acid mixture of $5 \mathrm{ml}$ of concentrated $\mathrm{H}_{2} \mathrm{SO}_{4}$ and $1 \mathrm{ml}$ of concentrated $\mathrm{HNO}_{3}$, which was heated to $\sim 385^{\circ} \mathrm{C}$ for 1 hour. The cooled solutions were diluted to into the 1 to $100 \mathrm{ppm}$ range depending on the metal concentration. Calibration standard curves were used to determine weight percent content for dopant metals and titanium. Magnetic susceptibility measurements were performed 
on solid powders at room temperature using a Johnson-Matthey MSB (Evans) magnetic susceptibility balance. Strongly magnetic samples were diluted in $\mathrm{NaCl}$ prior to analysis. All molar susceptibility results were was corrected for sample core diamagnetism for $\mathrm{TiO}_{2}$ of $2.9 \times 10^{-5} \mathrm{~cm}^{3} / \mathrm{mol}$ or $\mathrm{M}-\mathrm{TiO}_{2}$ of $2.98 \times 10^{-5} \mathrm{~cm}^{3} / \mathrm{mol}$. Spin-only magnetic moments were calculated from molar susceptibility per mole of dopant metal using $\mu_{\mathrm{B}}=2.83\left(\chi_{\mathrm{m}} \mathrm{x} \mathrm{T}\right)^{1 / 2}$. Scaled molar susceptibility was calculated by subtracting $\chi_{\mathrm{m}}$ from undoped SSM-TiO ${ }_{2}$ and dividing by the relative molar amount of $\mathrm{M}$ determined by $\mathrm{ICP}_{\mathrm{M}} \mathrm{M}_{\mathrm{x}} \mathrm{Ti}_{1-\mathrm{x}} \mathrm{O}_{2}$ structure. Solid diffuse reflectance UV-vis measurements were made with a LabSphere RSA accessory on an HP 8453 UV- vis spectrometer. The powders were physically embedded onto filter paper supports sandwiched between glass microscope slides. Each sample's diffuse reflectance (R) data was converted to Kubelka-Munk (K-M) units and plots of $F(R)=(1-R)^{2} / 2 R$ versus energy used to estimate absorption energy onsets or band gaps. The absorption onset data is derived from extrapolation of linear region of absorption rise down to baseline spectral region. Single baselines were used except for the Co- and Mn$\mathrm{TiO}_{2}$ data where different baselines better represented onset starting points of different regions. FT-IR spectra were obtained for each sample using KBr pellets in a Nicolet Nexus 760 spectrometer. X-ray photoelectron spectroscopy (XPS) data were obtained on a Kratos Axis Ultra Imaging spectrometer using monochromatic $\mathrm{Al} \mathrm{K}_{\alpha}$ radiation. Powders were embedded in indium foil for analysis. Survey spectra were obtained for acid washed samples (nominally 10 at\% $\mathrm{M}$ doped $\mathrm{TiO}_{2}$ ) and regional area spectra were obtained for Ti2p, O1s, as well as M2p ( $\mathrm{M}=\mathrm{Cr}$, Fe, Mn, Co, Ni, Cu). Peak positions are reported relative to the $\mathrm{C} 1 \mathrm{~s}$ peak at $284.5 \mathrm{eV}$. Semi-quantitative surface compositions and peak deconvolutions were performed using CasaXPS software package (www.casaxps.com) with a KratosAxis specific element library (KratosAxis-F1s.lib) and the following RSF factors: Ti2p (2.0), Cr 2p (2.43), Mn2p (2.66), Fe2p (2.96), Co2p (3.59), Ni (4.04), Cu (5.32). Relative atomic surface compositions were measured from survey scans.

2.4. Photocatalytic oxidative degradation of dyes. Photocatalytic oxidative degradation of methylene blue (MB) and methyl orange (MO) in air was performed using an Ace-Hanovia medium pressure $450 \mathrm{~W}$ mercury lamp in a water cooled Pyrex jacket. Approximately $10 \mathrm{mg}$ of doped and undoped titanias were loaded into $20 \mathrm{ml}$ pre-cleaned glass scintillation vials with $10 \mathrm{~mL}$ of a $3.00 \times 10^{-5} \mathrm{M}$ MB solution or $6.11 \times 10^{-5} \mathrm{M}$ MO solution and a stir bar. A dye sample with no powder was run as a blank. SSM synthesized undoped rutile $\mathrm{TiO}_{2}$ and Degussa P25 $\mathrm{TiO}_{2}$ ( 80\% anatase) samples were also used for comparison. The sample vials were placed on a large stir plate about $25 \mathrm{~cm}$ away from the mercury lamp, all of which were contained in a closed photochemical reactor cabinet. The samples were allowed to stir in the dark for 30 minutes to allow surface equilibration or adsorption of the MB or MO dye. UV irradiation was in regular intervals of 5 minutes or longer. Between each interval, the samples were 
centrifuged and UV-vis measurements were taken on the solution. The analyzed solutions were returned to the original vial and the irradiation was repeated. A similar set of experiments were performed using $420 \mathrm{~nm}$ cut off filters (Edmund Optics) to limit the UV lamp output to visible light wavelengths.

According to our testing, these cut off filters have a stop band limit or $0.001 \% \mathrm{~T}$ point at $430 \mathrm{~nm}$. Linear regression of $-\ln (\mathrm{C} / \mathrm{Co})$ versus time data for 4 data points in the first $20 \mathrm{~min}$ of UV irradiation (initial 40 min for visible) was used to estimate initial rate constants for MB dye degradation.

\section{Results and Discussion}

3.1. Synthesis of metal-doped titania via rapid SSM reactions. Rapid and exothermic selfpropagating SSM methods for the synthesis of inorganic metal oxide and non-oxide materials have broad flexibility to produce binary solids and more complex structures containing intimately mixed multiple metal and non-metal components. In the current study, we take advantage of the rapid and nonequilibrium exothermic processes of SSM reactions to incorporate moderate amounts of a second transition-metal into the rutile $\mathrm{TiO}_{2}$ structure. Typical thermodynamically driven methods for doping transition-metals into titania use sol-gel or solution precipitation methods followed by thermal processing, which leads to low metal dopant levels $(\sim 1 \%)$ in titania. Given the rapid heating/crystallization afforded by SSM reactions, there is potential for kinetically stabilized higher dopant level incorporation, thus we "overloaded" the reaction system with 10 at\% levels of dopant metals. Such additions, should impart visible optical absorption properties to the UV absorbing titania. The ideal SSM reactions for $\mathrm{MCl}_{2}$ dopants ( $\mathrm{Mn}, \mathrm{Co}, \mathrm{Ni}, \mathrm{Cu}$,) and $\mathrm{MCl}_{3}(\mathrm{Cr}, \mathrm{Fe})$ are shown below in Equations 2 and 3.

$$
\begin{aligned}
& 0.9 \mathrm{TiCl}_{3}+0.1 \mathrm{MCl}_{2}+1.45 \mathrm{Na}_{2} \mathrm{O}_{2} \rightarrow \mathrm{M}_{0.1} \mathrm{Ti}_{0.9} \mathrm{O}_{2}+0.45 \mathrm{O}_{2}+2.9 \mathrm{NaCl} \\
& 0.9 \mathrm{TiCl}_{3}+0.1 \mathrm{MCl}_{3}+1.5 \mathrm{Na}_{2} \mathrm{O}_{2} \rightarrow \mathrm{M}_{0.1} \mathrm{Ti}_{0.9} \mathrm{O}_{2}+0.5 \mathrm{O}_{2}+3 \mathrm{NaCl}
\end{aligned}
$$

In all cases, the SSM reactions were easily initiated in a self-propagating mode using a heated filament in the steel SSM reactor. The doped titania products (generally referred to as $\mathrm{M}-\mathrm{TiO}_{2}$ ) after water and acid workup were visibly colored, with colors generally consistent with the dopant metal in an oxide environment. Table 1 lists several qualitative and quantitative results obtained for these SSM M-TiO products with some of these results highlighted below. The isolated yields for the acid washed materials (assuming ideal $\mathrm{M}_{0.1} \mathrm{Ti}_{0.9} \mathrm{O}_{2}$ compositions) were generally in the $\sim 60$ - 80\% range. These yields likely reflect some $\mathrm{TiCl}_{3}$ loss via its decomposition to volatile $\mathrm{TiCl}_{4}$ during the highly exothermic SSM reaction. 
Table 1. Experimental conditions and results for acid-washed transition-metal doped titanias from rapid exothermic SSM reactions between $\mathrm{MCl}_{\mathrm{x}} / \mathrm{TiCl}_{3}$ and $\mathrm{Na}_{2} \mathrm{O}_{2}$ targeting $\mathrm{M}_{0.1} \mathrm{Ti}_{0.9} \mathrm{O}_{2}$.

\begin{tabular}{|lllll|}
\hline $\mathbf{M}-\mathbf{T i O}_{2}$ & $\mathbf{M C l}_{\mathbf{x}}$ & XRD $^{\mathbf{1}}$ & $\begin{array}{l}\text { Product color, } \\
\text { percent yield }\end{array}$ & $\begin{array}{l}\text { ICP (EDS) analysis } \\
\text { Ti:M molar ratio }\end{array}$ \\
\hline $\mathrm{Cr}-\mathrm{TiO}_{2}$ & $\mathrm{CrCl}_{3}$ & rutile $\mathrm{TiO}_{2}$ & yellow, 71\% & $1.0: 0.037(1.0: 0.046)$ \\
\hline $\mathrm{Mn}-\mathrm{TiO}_{2}$ & $\mathrm{MnCl}_{2}$ & rutile $\mathrm{TiO}_{2}$ & brown, 86\% & $1.0: 0.104(1.0: 0.174)$ \\
\hline $\mathrm{Fe}-\mathrm{TiO}_{2}$ & $\mathrm{FeCl}_{3}$ & rutile $\mathrm{TiO}_{2}$ & lt brown, 73\% & $1.0: 0.063(1.0: 0.061)$ \\
\hline $\mathrm{Co}^{-\mathrm{TiO}_{2}}$ & $\mathrm{CoCl}_{2}$ & rutile $\mathrm{TiO}_{2}$ & green, 68\% & $1.0: 0.102(1.0: 0.115)$ \\
\hline $\mathrm{Ni}^{-\mathrm{TiO}_{2}}$ & $\mathrm{NiCl}_{2}$ & rutile $\mathrm{TiO}_{2}$ & grey, 67\% & $1.0: 0.042(1.0: 0.090)$ \\
\hline $\mathrm{Cu}-\mathrm{TiO}_{2}$ & $\mathrm{CuCl}_{2}$ & rutile $\mathrm{TiO}_{2}$ & lt brown, 58\% & $1.0: 0.069(1.0: 0.115)$ \\
\hline
\end{tabular}

1) Minor crystalline secondary phases were sometimes observed (see text for details).

XRD data showed the presence of Na-Ti-O phases (e.g., $\mathrm{Na}_{2} \mathrm{Ti}_{6} \mathrm{O}_{13}$ ), consistent with our earlier $\mathrm{SSM} \mathrm{TiO}_{2}$ work. ${ }^{47}$ An acid wash step removed most detectable $\mathrm{NaTi}_{\mathrm{x}} \mathrm{O}_{\mathrm{y}}$ impurities. EDS data from water versus acid washed samples show that the acid wash significantly decreases sodium content along with removing some dopant metal. Powder XRD data in Figure 2 demonstrates that acid-washed metal-doped titanias are primarily crystalline rutile $\mathrm{TiO}_{2}(\mathrm{PDF} \# 21-1276)$. The rutile $\mathrm{TiO}_{2}$ phase is expected as these SSM reactions can reach transient temperatures over $1300^{\circ} \mathrm{C}$ and so it would be difficult to produce the lowtemperature anatase $\mathrm{TiO}_{2}$ phase under such conditions. Some acid washed samples still show evidence of $\mathrm{Na}_{2} \mathrm{Ti}_{9} \mathrm{O}_{19}$ (PDF \#78-1590) and $\mathrm{Na}_{2} \mathrm{Ti}_{6} \mathrm{O}_{13}$ (PDF \#37-0951) impurities. The $\mathrm{Ni}-\mathrm{TiO}_{2}$ sample shows two small peaks consistent with $\mathrm{NiO}$ and the $\mathrm{Co}-\mathrm{TiO}_{2}$ sample has small peaks that may be $\mathrm{Co}_{2} \mathrm{TiO}_{4}(\mathrm{PDF} \# 39$ 1410), though some of these small peaks overlap with Na-Ti-O phases.

Selected acid-washed samples were annealed in air at $1000^{\circ} \mathrm{C}$ to examine whether metal dopant segregation was observed. Given the high dopant levels in these $\mathrm{M}-\mathrm{TiO}_{2}$ materials, it is not surprising that crystalline metal titanate or Na-M-Ti-O phases are observed after prolonged high temperature annealing. In most annealed products, the major phase remains rutile $\mathrm{TiO}_{2}$ (except for Co where $\mathrm{Na}_{2} \mathrm{CoTi}_{7} \mathrm{O}_{16}$ is dominant) with new minor phases seen for $\mathrm{Cr}\left(\mathrm{Na}_{2} \mathrm{Cr}_{2} \mathrm{Ti}_{6} \mathrm{O}_{16}\right), \mathrm{Mn}\left(\mathrm{Na}_{2} \mathrm{Mn}_{2} \mathrm{Ti}_{6} \mathrm{O}_{16}\right), \mathrm{Fe}$ $\left(\mathrm{Na}_{2} \mathrm{Fe}_{3} \mathrm{Ti}_{6} \mathrm{O}_{16}\right)$, $\mathrm{Ni}\left(\mathrm{NiTiO}_{3}, \mathrm{Na}_{0.23} \mathrm{TiO}_{2}, \mathrm{NiO}\right)$, and $\mathrm{Cu}\left(\mathrm{Na}_{0.86} \mathrm{Cu}_{0.43} \mathrm{Ti}_{3.57} \mathrm{O}_{8}, \mathrm{NaCu}_{2.5} \mathrm{Ti}_{4.5} \mathrm{O}_{12}\right)$. This provides further support that the rapid SSM reactions trap dopants in non-thermodynamic compositions and structures that will convert to thermodynamically preferred structures upon annealing. 


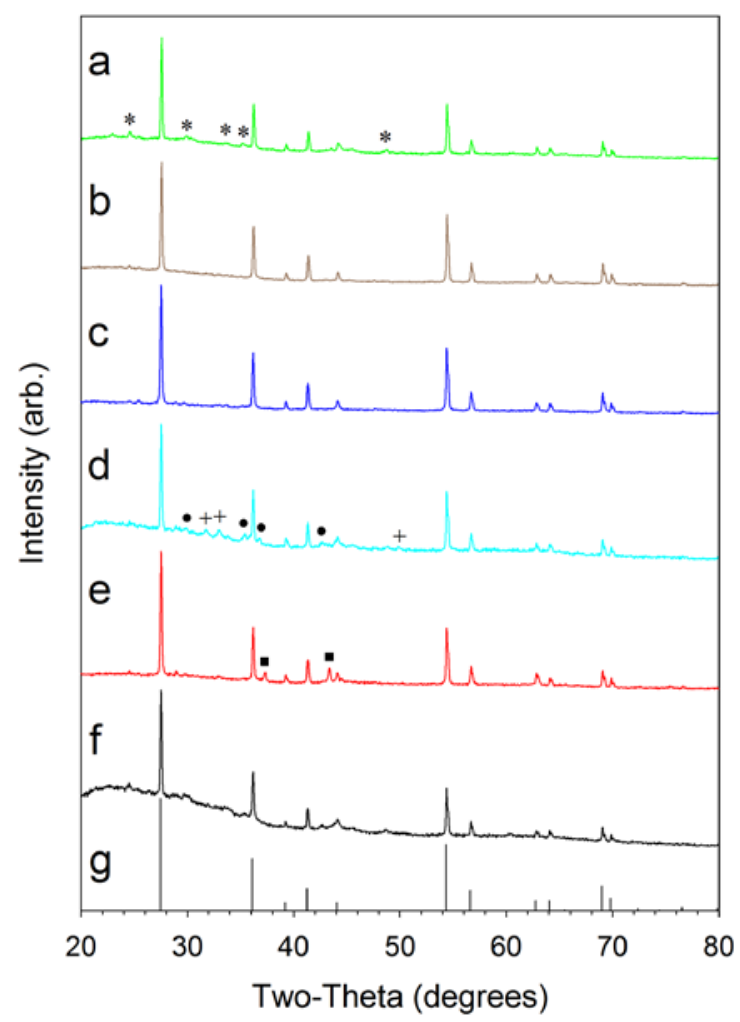

Figure 2. Powder XRD data for acid-washed $\mathrm{M}-\mathrm{TiO}_{2}$ samples produced by SSM reactions where $\mathrm{M}=(\mathrm{a})$ $\mathrm{Cr}$, (b) $\mathrm{Mn}$, (c) Fe, (d) Co, (e) $\mathrm{Ni}$, (f) $\mathrm{Cu}$. The standard peak positions for crystalline rutile $\mathrm{TiO}_{2}$ are shown in (g). The * marks $\mathrm{Na}_{2} \mathrm{Ti}_{9} \mathrm{O}_{19}, \bullet$ marks $\mathrm{Co}_{2} \mathrm{TiO}_{4},+$ marks $\mathrm{Na}_{2} \mathrm{Ti}_{6} \mathrm{O}_{13}$, and marks $\mathrm{NiO}$.

3.2. Compositional analysis of SSM synthesized metal-doped titanias. In contrast to typically low $\sim 1 \%$ metal dopant levels found in solution methods to metal doped titanias, the ICP results show the SSM synthesized ${\mathrm{M}-\mathrm{TiO}_{2}}_{2}$ materials have a much higher bulk dopant metal content (Table 1). The transitionmetal dopant levels range near the targeted Ti:M ratio for $\mathrm{M}_{0.1} \mathrm{Ti}_{0.9} \mathrm{O}_{2}$ of $1: 0.11$ down $\sim 1: 0.05$. Both ICP and EDS data for these acid-washed SSM reaction products show that they retain significant amounts of dopant metal. Some of the semiquantitative EDS results show higher dopant content than the more quantitative standardized ICP measurements, which may indicate some higher dopant concentrations on the particle surface.

The acid-washed $\mathrm{M}-\mathrm{TiO}_{2}$ powders were analyzed by XPS to examine relative composition of metals on the surface and chemical states of the surface species. Table 2 summarizes survey and regional scan data for the metal doped titania powders. In most cases, the semiquantitative surface compositions (Ti:M ratios) for the powders is comparable to the bulk analysis results described earlier, with a few notable exceptions. While the bulk and most of the surface analysis results support that the achieved dopant levels are generally less than the targeted $\mathrm{M}_{0.1} \mathrm{Ti}_{0.9} \mathrm{O}_{2}$ product, both the $\mathrm{Cr}$ and $\mathrm{Mn}$ doped samples show 
very high surface metal dopant amounts relative to their bulk compositions. This result was verified on several different products. The high dopant surface content may impact molecular dye adsorption discussed later in this chapter. In comparing ICP with EDS or XPS data in Tables 1 and 2, it appears that the high dopant contents targeted in these short-lived SSM reactions lead to dopant rich near surface regions even if not detected by XRD analysis, specifically observed for $\mathrm{Cr}$, Mn, and Ni doped titanias.

Degussa $\mathrm{P} 25-\mathrm{TiO}_{2}$ yields a Ti $2 \mathrm{p}_{3 / 2}$ XPS peak at $458.3 \mathrm{eV}$ and undoped $\mathrm{SSM}-\mathrm{TiO}_{2}$ has a peak at 458.2 $\mathrm{eV}$, which are very near literature titania values. ${ }^{49}$ The $\mathrm{Ti} 2 \mathrm{p}_{3 / 2}$ binding energies for metal-doped $\mathrm{TiO}_{2}$ in Table 2 are generally close to the pure $\mathrm{TiO}_{2}$ values, but several are shifted to lower energies that may indicate some reduced $\mathrm{Ti}^{3+}$ on the surface. The commercial $\mathrm{P} 25-\mathrm{TiO}_{2}$ and $\mathrm{SSM}-\mathrm{TiO}_{2}$ have one major oxygen O1s chemical environment at $\sim 529.5 \mathrm{eV}$, which is also the major oxygen surface environment found in the $\mathrm{M}-\mathrm{TiO}_{2}$ samples, in addition smaller peak intensity in the $\sim 530-532 \mathrm{eV}$ region for oxide environments due to the metal dopants. The metal dopant's $2 \mathrm{p}_{3 / 2}$ peak positions listed in Table 2 are consistent with binary oxide metal oxidation states, for example (lit. value, eV) $\mathrm{Cr}^{3+}$ (576.9), $\mathrm{Mn}^{4+}$ (642.1), $\mathrm{Fe}^{3+}$ (710.8), $\mathrm{Co}^{2+}(780.6)$ and $\mathrm{Ni}^{2+}$ (855.6), and $\mathrm{Cu}^{2+}$ (933.6) ${ }^{50-55}$ There may be some $\mathrm{Cu}^{+}$ present in the $\mathrm{Cu}-\mathrm{TiO}_{2}$.

Table 2. Summary of XPS Analysis on $\mathrm{M}-\mathrm{TiO}_{2}$ Powders

\begin{tabular}{|c|c|c|c|}
\hline Compound & $\begin{array}{l}\begin{array}{l}\text { Surface Ti:M } \\
\text { (rel. molar ratio) }\end{array} \\
\end{array}$ & $\mathrm{Ti}_{2} \mathrm{p}_{3 / 2}$ transition $(\mathrm{eV})$ & $\mathrm{M}^{2} \mathbf{p}_{3 / 2}$ transitions $(\mathrm{eV})^{1}$ \\
\hline $\mathrm{Cr}-\mathrm{TiO}_{2}$ & $1: 0.384$ & 458.3 & 576.8, 579.4 \\
\hline $\mathrm{Mn}-\mathrm{TiO}_{2}$ & $1: 0.599$ & 458.0 & $641.3,642.7$ \\
\hline $\mathrm{Fe}-\mathrm{TiO}_{2}$ & $1: 0.064$ & 458.4 & $710.7,712.7$ \\
\hline $\mathrm{Co}-\mathrm{TiO}_{2}$ & $1: 0.109$ & 458.2 & $\begin{array}{l}\text { 780.1, 782.0, } \\
\text { 784.6, 786.5 }\end{array}$ \\
\hline $\mathrm{Ni}-\mathrm{TiO}_{2}$ & $1: 0.100$ & 458.2 & 855.3, 861.4 \\
\hline $\mathrm{Cu}-\mathrm{TiO}_{2}$ & $1: 0.089$ & 457.2 & $\begin{array}{l}\text { 931.4, 932.8, 933.7, } \\
\text { 939.8, 942.3 }\end{array}$ \\
\hline
\end{tabular}

1) major transition(s) from peak deconvolution are bolded.

3.3. Morphologies of SSM synthesized metal-doped titanias. SEM analysis of $\mathrm{M}-\mathrm{TiO}_{2}$ samples shows a range of particle sizes and shapes, consistent with that expected from a rapid exothermic reaction where powder products reside in a molten $\mathrm{NaCl}$ salt flux for a very short time. Figure 3 shows representative images for the $\mathrm{M}-\mathrm{TiO}_{2}$ powders that were lightly pressed into pellets (additional loose powder images are in Supporting Information Figure S1). The samples are fairly heterogeneous in size and shape, with 
distinct facets visible on some crystallites faces. Particles with roughly spherical shapes and aggregates are visible as are larger faceted and elongated rod-like structures. The particles roughly range from $~ 500$ $\mathrm{nm}$ to 5 micrometers, though much larger 10 - 30 micrometer crystallites are also visible. The welldefined crystallite structures and relative large particles observed from this SSM reaction may be a direct result of the initial powder forming in a byproduct molten salt flux that would aid in product crystallization and growth.

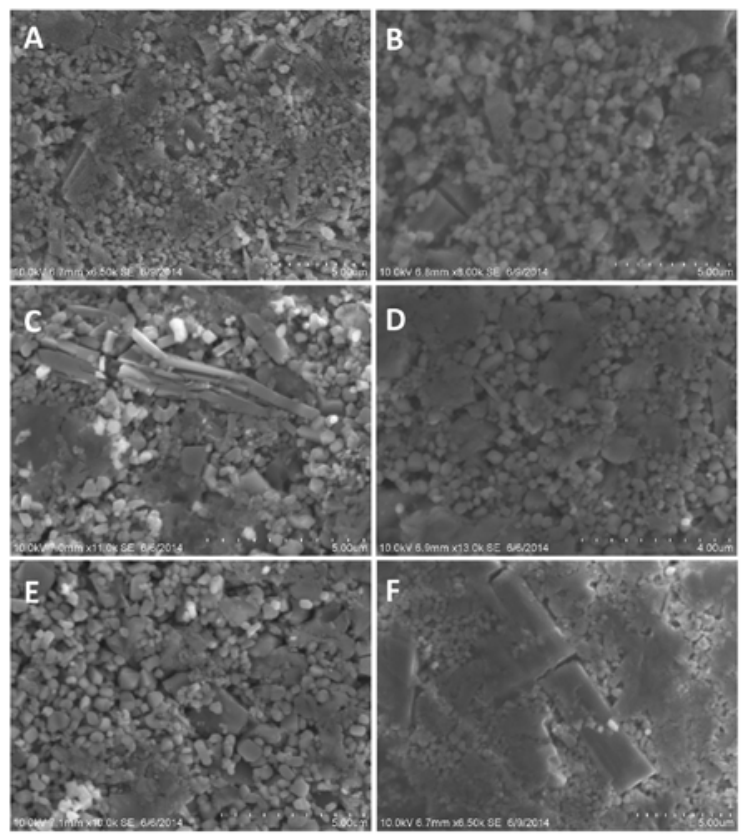

Figure 3. Representative SEM images for $\mathrm{M}-\mathrm{TiO}_{2}$ materials with $\mathrm{M}=\mathrm{Cr}$ (A), $\mathrm{Mn}$ (B), $\mathrm{Fe}(\mathrm{C})$, Co (D), $\mathrm{Ni}(\mathrm{E})$, and $\mathrm{Cu}(\mathrm{F})$.

3.4. Magnetic and optical properties of metal-doped titanias. The room-temperature magnetic susceptibilities of the $\mathrm{M}-\mathrm{TiO}_{2}$ samples are listed in Table 3. Undoped $\mathrm{SSM}^{-\mathrm{TiO}_{2}}$ shows a small paramagnetic response likely due to either some low level $\mathrm{Ti}^{3+}$ or other magnetic metal content from either steel reactor or nichrome wire. The paramagnetic responses from metal-doped titanias are all much larger than that for undoped $\mathrm{TiO}_{2}$ and should be due to the dopant metal. The paramagnetic response from acid-washed $\mathrm{M}-\mathrm{TiO}_{2}$ samples is generally larger for more heavily doped materials. A estimate of magnetic moment per mole of dopant metal is listed in Table $3(\sim 3.4-7.5 \mathrm{BM})$ and most values fall in a range expected for spin-only paramagnetic metal ions with several unpaired d electrons $(n=1$ to 5 unpaired electrons with 1.7 to $5.9 \mathrm{BM}$ ). If one assumes that dopant ions are ideal spin-only paramagnets, then the values in Table 3 roughly correspond to $\mathrm{Cr}^{2+}, \mathrm{Mn}^{4+}, \mathrm{Fe}^{3+}, \mathrm{Co}^{3+}$, with the $\mathrm{Ni}$ and $\mathrm{Cu}$ values exceeding that expected for $\mathrm{Ni}^{2+}$ or $\mathrm{Cu}^{2+}$. The magnetic measurements along with XPS show that metal ions are in oxidized states and possibly clustered together leading to enhanced magnetic behavior. 
Table 3. Room-temperature magnetic and optical results on $\mathrm{M}-\mathrm{TiO}_{2}$ powders from $\mathrm{SSM}$ reactions.

\begin{tabular}{|c|c|c|c|c|}
\hline $\mathrm{M}^{-\mathrm{TiO}_{2}}$ & $\begin{array}{l}\text { Mass }\left(\chi_{\mathrm{g}}, \mathrm{cm}^{3} / \mathrm{g}\right) \text { and } \\
\text { molar }\left(\chi_{\mathrm{m}}, \mathrm{cm}^{3} / \mathrm{mol}\right) \\
\text { magnetic susceptibility }\end{array}$ & $\begin{array}{l}\text { Magnetic } \\
\text { moment per } \\
\text { mol M (BM) }\end{array}$ & $\begin{array}{l}\text { UV-vis absorbance in } \\
\text { nm (type, } E \text { in } \mathrm{eV})^{2}\end{array}$ & $\begin{array}{l}\text { Absorption energy } \\
\text { onsets (eV) from } \\
\text { K-M analysis } \\
\end{array}$ \\
\hline $\mathrm{TiO}_{2}(\mathrm{P} 25)$ & $\begin{array}{l}\chi_{\mathrm{g}}=-0.0098 \times 10^{-6} \\
\chi_{\mathrm{m}}=+0.298 \times 10^{-4}\end{array}$ & 0.27 & $408(0,3.04)$ & 3.05 \\
\hline $\mathrm{TiO}_{2}(\mathrm{SSM})$ & $\begin{array}{l}\chi_{\mathrm{g}}=+0.609 \times 10^{-6} \\
\chi_{\mathrm{m}}=+0.775 \times 10^{-4}\end{array}$ & 0.43 & $415(0,2.99)$ & 3.00 \\
\hline $\mathrm{Cr}-\mathrm{TiO}_{2}$ & $\begin{array}{l}\chi_{\mathrm{g}}=+6.34 \times 10^{-6} \\
\chi_{\mathrm{m}}=+5.39 \times 10^{-4}\end{array}$ & 5.7 & $\begin{array}{l}570(\mathrm{o}, 2.18), 700(\mathrm{p}, \\
1.77), 800(\mathrm{o}, 1.55)\end{array}$ & $2.15,1.50$ \\
\hline $\mathrm{Mn}-\mathrm{TiO}_{2}$ & $\begin{array}{l}\chi_{\mathrm{g}}=+7.55 \times 10^{-6} \\
\chi_{\mathrm{m}}=+6.38 \times 10^{-4}\end{array}$ & 3.8 & $\begin{array}{l}670(\mathrm{o}, 1.85), 710(\mathrm{p}, \\
1.75), 920(\mathrm{o}, 1.35)\end{array}$ & $1.80,1.35$ \\
\hline $\mathrm{Fe}-\mathrm{TiO}_{2}$ & $\begin{array}{l}\chi_{\mathrm{g}}=+17.1 \times 10^{-6} \\
\chi_{\mathrm{m}}=+14.1 \times 10^{-4}\end{array}$ & 7.5 & $\begin{array}{l}480 \text { (o, 2.59), } 490 \text { (p, } \\
2.53), 580(\mathrm{o}, 2.53)\end{array}$ & $2.45,2.10$ \\
\hline Co- $\mathrm{TiO}_{2}$ & $\begin{array}{l}\chi_{\mathrm{g}}=+11.2 \times 10^{-6} \\
\chi_{\mathrm{m}}=+9.35 \times 10^{-4}\end{array}$ & 4.7 & $\begin{array}{l}510(\mathrm{o}, 2.43), 580(\mathrm{p}, \\
2.14), 660(\mathrm{p}, 1.88), \\
800(\mathrm{o}, 1.55)\end{array}$ & $2.40,1.60$ \\
\hline $\mathrm{Ni}-\mathrm{TiO}_{2}$ & $\begin{array}{l}\chi_{\mathrm{g}}=+7.54 \times 10^{-6} \\
\chi_{\mathrm{m}}=+6.40 \times 10^{-4}\end{array}$ & 6.0 & $\begin{array}{l}500(\mathrm{o}, 2.48), 740(\mathrm{p}, \\
1.68), 810(\mathrm{o}, 1.53)\end{array}$ & $2.55,1.55$ \\
\hline $\mathrm{Cu}-\mathrm{TiO}_{2}$ & $\begin{array}{l}\chi_{\mathrm{g}}=+4.20 \times 10^{-6} \\
\chi_{\mathrm{m}}=+3.72 \times 10^{-4}\end{array}$ & 3.4 & $\begin{array}{l}490 \text { (o, 2.53), } 740 \text { (p, } \\
1.68)\end{array}$ & 2.55 \\
\hline
\end{tabular}

1) Estimated spin-only magnetic moment at $298 \mathrm{~K}$ for $\mathrm{M}-\mathrm{TiO}_{2}$ samples calculated from $\chi_{\mathrm{m}}$ due to metal dopant (total $\chi_{\mathrm{m}}-\chi_{\mathrm{m}}$ for undoped $\mathrm{SSM} \mathrm{TiO}$ ) and scaled per mol M-TiO $\mathrm{T}_{2}$ based on $\mathrm{ICP}_{\text {composition. }}$ Degussa $\mathrm{P} 25-\mathrm{TiO}_{2}$ and $\mathrm{SSM}-\mathrm{TiO}_{2}$ moments are per mole of $\mathrm{TiO}_{2}$.

2) $\mathrm{p}=$ broad absorption peak, $\mathrm{o}=$ onset of absorption event.

The solid-state optical absorption properties of the SSM-synthesized $\mathrm{M}^{-\mathrm{TiO}_{2}}$ materials were examined by diffuse reflectance UV-vis spectroscopy. In contrast to white commercial $\mathrm{P} 25 \mathrm{TiO}_{2}$, the metal-doped titanias are all visibly colored powders (see Table 1) and show a range of visible light absorption.

Undoped SSM rutile $\mathrm{TiO}_{2}$ has a visible off-white beige color even after acid washing, possibly due to some $\mathrm{Ti}^{3+}$ content, but shows little detectable visible absorption versus the $\mathrm{M}-\mathrm{TiO}_{2}$ materials. Table 3 lists approximate absorption wavelengths and energies for the $\mathrm{M}-\mathrm{TiO}_{2}$ products. The extrapolated onset absorption energy for commercial $\mathrm{P} 25 \mathrm{TiO}_{2}$ and $\mathrm{SSM}_{-} \mathrm{TiO}_{2}$ samples is near $3 \mathrm{eV}$, while the $\mathrm{M}-\mathrm{TiO}_{2}$ samples show red-shifted lower energy absorptions ( 1.8 - $2.6 \mathrm{eV})$ and several show with additional absorption further in the visible region around $500-750 \mathrm{~nm}(\sim 1.7-2.5 \mathrm{eV})$. Optical absorption properties are consistent with transition-metal ions present in the titania. An examination of low energy valence band region of the XPS spectra for $\mathrm{M}-\mathrm{TiO}_{2}$ samples indicates that dopants may raise the valence band energy level that would lead to smaller band gaps, however uncertainty and low intensity of the data, makes this a qualitative observation. 


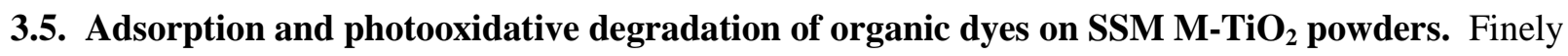
ground $\mathrm{M}-\mathrm{TiO}_{2}$ powders suspended in aqueous methylene blue (MB) dye solutions were irradiated with broad spectrum UV illumination with periodic analysis of dye remaining in solution using UV-vis spectroscopy. The MB dye contains a heterocyclic ring with N/S atoms that is oxidatively degradable by oxygen on a catalyst surface. For comparison purposes, undoped rutile $\mathrm{SSM}_{-} \mathrm{TiO}_{2}\left(\mathrm{SSM}^{-\mathrm{TiO}_{2}}\right)$ and a commercial anatase standard powder ( $\sim 50 \mathrm{~nm}$ particles Degussa $\mathrm{P} 25-\mathrm{TiO}_{2}$ ) were analyzed along with the $\mathrm{M}-\mathrm{TiO}_{2}$ samples. The results are shown in Figure 4. On notable difference for many $\mathrm{M}-\mathrm{TiO}_{2}$ samples versus $\mathrm{P} 25-\mathrm{TiO}_{2}$ was observed moderate or large degree ( 40-90\%) of dye surface adsorption that occurred during the 30 minute dark equilibration step. This is a fairly reversible process as the $\mathrm{Mn}^{-\mathrm{TiO}_{2}}$ after dark dye equilibration will easily release its adsorbed dye when placed in methanol. After several hours of UV irradiation, $\mathrm{SSM}_{-} \mathrm{TiO}_{2}$ and the $\mathrm{M}-\mathrm{TiO}_{2}$ samples (except the chromium and cobalt samples) retain a bluish color consistent with some adsorbed intact MB dye and leaving very pale colored blue solutions.
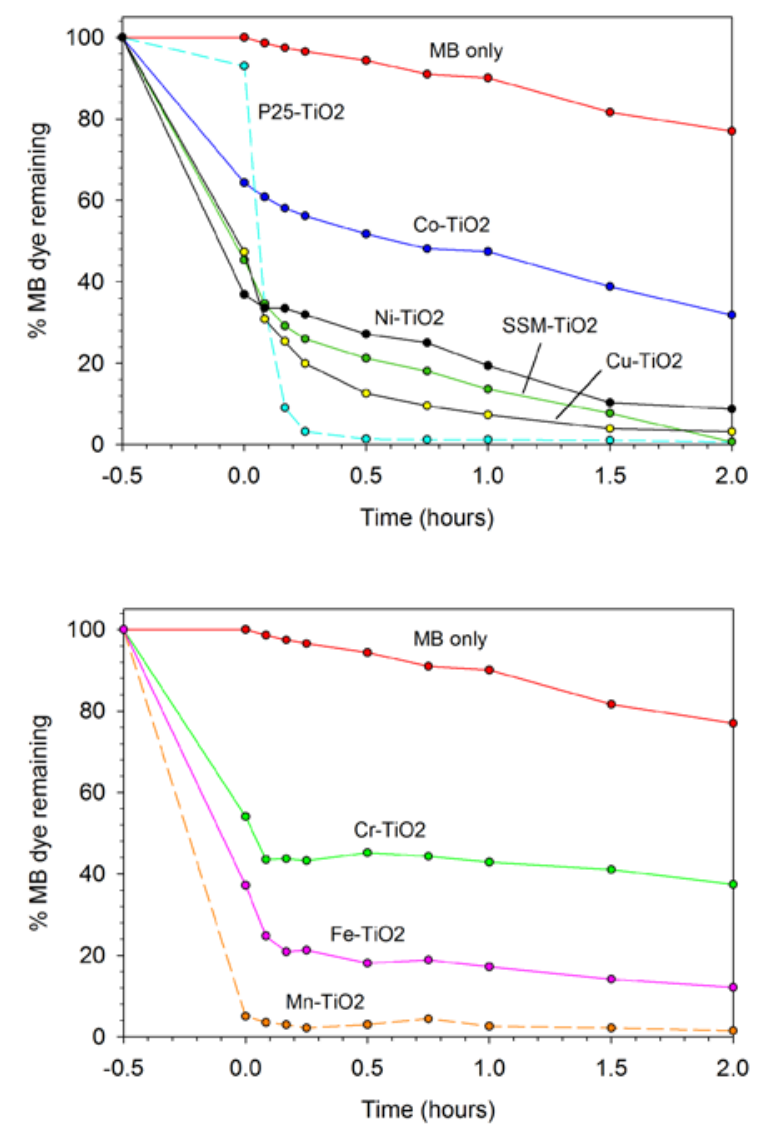

Figure 4. Absorption and UV photodegradation of methylene blue (MB) by $\mathrm{M}-\mathrm{TiO}_{2}$ powders. The first half hour is equilibration of dye solution in the dark (surface adsorption) and light was turned on at time $=$ 0 hours. 
For comparison, highly active commercial anatase-rich $\mathrm{P} 25 \mathrm{TiO}_{2}$ is more photoactive than these rutile samples and clears dye from the solution after $\sim 30 \mathrm{~min}$ of UV exposure. (Supporting Information Figure S2). Table 4 shows dark absorption and total dye degradation amounts after subsequent $2 \mathrm{hr}$ UV irradiation where the most photoactive samples reach high dye degradation values. The initial degradation data was used to calculate approximate first order rate constants from the data (Supporting Information Figure S3). As shown in Table 4, in addition to high dark dye adsorption, $\mathrm{Mn}, \mathrm{Fe}$, and $\mathrm{Cu}$ doped samples show respectable dye degradation comparable to the undoped $\mathrm{TiO}_{2}$ sample.

Table 4. Summary of methylene blue dye absorption and photodegradation on $\mathrm{M}-\mathrm{TiO}_{2}$

\begin{tabular}{|c|c|c|c|c|}
\hline Compound & $\begin{array}{l}\text { Total MB \% loss } \\
\text { after } 2 \text { hr UV [\% loss } \\
\text { from dark absorb] }\end{array}$ & $\begin{array}{l}\text { Rate constant } \\
\mathbf{k}\left(\mathbf{h r}^{-1}\right) \text { for UV } \\
\text { MB degrad. } \\
\end{array}$ & $\begin{array}{l}\text { Total MB \% loss } \\
\text { after } 4 \mathrm{hr} \text { vis [\% loss } \\
\text { from dark absorb] } \\
\end{array}$ & $\begin{array}{l}\text { Rate constant } k \\
\left(h^{-1}\right) \text { for vis MB } \\
\text { degrad. }\end{array}$ \\
\hline MB alone & $23[\mathrm{n} / \mathrm{a}]$ & $0.14(1)$ & $23[\mathrm{n} / \mathrm{a}]$ & $0.11(2)$ \\
\hline $\mathrm{P}^{25}-\mathrm{TiO}_{2}$ & 98 [7] (after 0.5 hr) & 13.7(5) & $\begin{array}{c}79 \text { [22] } \\
\text { annealed: } 45 \text { [5] }\end{array}$ & $\begin{array}{c}0.42(5) \\
\text { annealed: } 0.26(3)\end{array}$ \\
\hline $\mathrm{SSM}^{-\mathrm{TiO}_{2}}$ & 99 [55] & $2.2(3)$ & $79[43]$ & $0.29(7)$ \\
\hline $\mathrm{Cr}-\mathrm{TiO}_{2}$ & $63[46]$ & $0.8(4)$ & $67[50]$ & no MB loss \\
\hline $\mathrm{Mn}^{-\mathrm{TiO}_{2}}$ & 99 [95] & $3.2(3)$ & $97[62]$ & $1.7(4)$ \\
\hline Fe-TiO ${ }_{2}$ & 88 [63] & $2.2(8)$ & 90 [81] & $1.9(8)$ \\
\hline $\mathrm{Co}-\mathrm{TiO}_{2}$ & $68[36]$ & $0.54(4)$ & $78[46]$ & $0.35(7)$ \\
\hline $\mathrm{Ni}-\mathrm{TiO}_{2}$ & $91[63]$ & $0.5(1)$ & $69[45]$ & $0.12(9)$ \\
\hline $\mathrm{Cu}-\mathrm{TiO}_{2}$ & $97[53]$ & $3.3(4)$ & $86[48]$ & $0.8(4)$ \\
\hline
\end{tabular}

Similar UV experiments were performed with a methyl orange (MO) dye, which has an azo nitrogen double bond linking two heterocyclic rings. The rutile $\mathrm{M}-\mathrm{TiO}_{2}$ samples absorb little $\mathrm{MO}$ dye during dark equilibration and were less photocatalytically active leaving 80-95\% MO dye in solution after 4 hrs of UV irradiation. For comparison, anatase $\mathrm{P} 25-\mathrm{TiO}_{2} \mathrm{UV}$ photodegrades $~ 100 \%$ of the MO dye after $2.5 \mathrm{hrs}$ leaving a clear, colorless solution and a white solid. Thus either the rutile structure or interference from metal dopant makes them less effective for MO dye degradation.

Given the visible absorption properties of $\mathrm{M}-\mathrm{TiO}_{2}$ powders, the visible light photocatalytic degradation of MB dye was investigated with filtered UV (>420 nm). Dark equilibrium dye absorption is again 
significant for most $\mathrm{M}-\mathrm{TiO}_{2}$ samples, though magnitudes vary from earlier UV studies, suggesting surface charge of $\mathrm{M}-\mathrm{TiO}_{2}$ samples may impact degree of $\mathrm{MB}$ absorption. Upon visible light irradiation, several $\mathrm{M}-\mathrm{TiO}_{2}$ samples showed photodegradation activity towards $\mathrm{MB}$, but at reduced rates versus the $\mathrm{UV}$ experiments (Figure 5). Due to UV filtering, both $\mathrm{P} 25-\mathrm{TiO}_{2}$ and annealed $\mathrm{P} 25-\mathrm{TiO}_{2}$ (rutile phase) samples showed significantly lower dye degradation. Table 4 shows comparison of MB photodegradation after 4 hour visible light versus 2 hours of UV illumination. While significant visible light assisted MB removal is seen for most samples, only Mn and Fe samples cause dye elimination of $90 \%$ or greater.
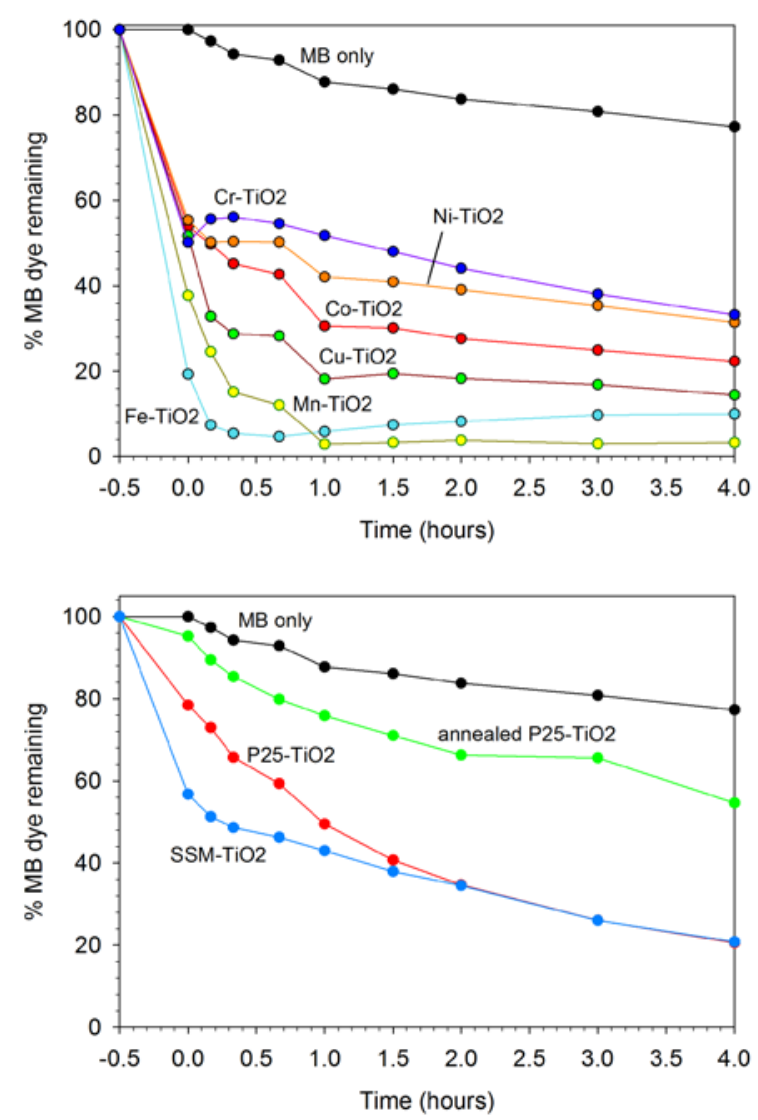

Figure 5. Visible light methylene blue photodegradation by $\mathrm{M}-\mathrm{TiO}_{2}$ powders. The first half hour is equilibration of dye solution in the dark (surface adsorption) and light was turned on at time $=0$ hours.

\section{Conclusions}

Rapid SSM reactions are capable of incorporating relatively large amounts of dopant metals into titania during the short-lived exothermic reaction. The targeted Ti:M bulk molar ratio was 1:0.11 with actual analyzed values being generally at or below the target value. The nature of the rapid SSM reaction that involves rapid cooling from a molten salt may impact the degree of metal dopant incorporation and 
observed sodium titanate components. The washed doped rutile $\mathrm{TiO}_{2}$ materials show optical, magnetic, and structural properties consistent with dopant primarily residing in the oxide structure, though some samples show surface enrichment of dopant content. Several of the $\mathrm{M}-\mathrm{TiO}_{2}$ products show both $\mathrm{UV}$ and visible photodegradation activity for a methylene blue dye. In the case of visible light experiments, several $\mathrm{M}-\mathrm{TiO}_{2}$ samples more effectively used the incoming light for photodegradation than the P25 anatase titania standard. All $\mathrm{M}-\mathrm{TiO}_{2}$ samples demonstrated significant dark dye adsorption that may aid in bringing the dye near oxygen and photogenerated electron/hole pairs that perform the dye oxidation.

\section{Acknowledgements}

The University of Iowa's GAANN fellowship program (N. C.) and National Science Foundation (E. G., Grant \#CHE-0957555) are gratefully thanked for partial support for this research. The NSF REU summer program (Grant \# CHE-1062575) supported Joey Squires, Liam Taylor, and Tyler Van Heest who are thanked for their early contributions to this work. Jonas Baltrusaitus and Sylvia Lee are thanked for XPS data acquisition assistance. 


\section{References}

1. Antonello, A.; Soliveri, G.; Meroni, D.; Cappelletti, G.; Ardizzone, S., Photocatalytic remediation of indoor pollution by transparent TiO2 films. Catalysis Today 2014, 230, 35-40.

2. Z Zhu, W.; Tong, D. L.; Xu, J. B.; Liu, Y.; Ma, J., Multifunctional composite multilayer coatings on glass with self-cleaning, hydrophilicity and heat-insulating properties. Thin Solid Films 2012, 526, 201-211.

3. Hanaor, D. A. H.; Sorrell, C. C., Review of the anatase to rutile phase transformation. Journal of Materials Science 2011, 46 (4), 855-874.

4. Bacsa, R. R.; Kiwi, J., Effect of rutile phase on the photocatalytic properties of nanocrystalline titania during the degradation of p-coumaric acid. Applied Catalysis B: Environmental 1998, 16 (1), 19-29.

5. Luo, Z.; Poyraz, A. S.; Kuo, C.-H.; Miao, R.; Meng, Y.; Chen, S.-Y.; Jiang, T.; Wenos, C.; Suib, S. L., Crystalline Mixed Phase (Anatase/Rutile) Mesoporous Titanium Dioxides for Visible Light Photocatalytic Activity. Chemistry of Materials 2015, 27 (1), 6-17.

6. Fujishima, A.; Honda, K., Electrochemical Photolysis of Water at a Semiconductor Electrode. Nature 1972, 238 (5358), 37-+.

7. Subramanian, V.; Wolf, E. E.; Kamat, P. V., Catalysis with TiO2/gold nanocomposites. Effect of metal particle size on the Fermi level equilibration. J Am Chem Soc 2004, 126 (15), 4943-50.

8. Bamwenda, G. R.; Tsubota, S.; Nakamura, T.; Haruta, M., The influence of the preparation methods on the catalytic activity of platinum and gold supported on TiO2 for CO oxidation. Catalysis Letters 1997, 44 (1-2), 83-87.

9. $\quad$ Hagfeldt, A.; Gratzel, M., Molecular photovoltaics. Acc Chem Res 2000, 33 (5), 269-77.

10. Likodimos, V.; Han, C.; Pelaez, M.; Kontos, A. G.; Liu, G.; Zhu, D.; Liao, S.; de la Cruz, A. A.; O’Shea, K.; Dunlop, P. S. M.; Byrne, J. A.; Dionysiou, D. D.; Falaras, P., Anion-Doped TiO2Nanocatalysts for Water Purification under Visible Light. Industrial \& Engineering Chemistry Research 2013, 52 (39), 13957-13964.

11. Serpone, N., Is the band gap of pristine $\mathrm{TiO}(2)$ narrowed by anion- and cation-doping of titanium dioxide in second-generation photocatalysts? J Phys Chem B 2006, 110 (48), 24287-93.

12. Diwald, O.; Thompson, T. L.; Zubkov, T.; Walck, S. D.; Yates, J. T., Photochemical Activity of Nitrogen-Doped Rutile TiO2(110) in Visible Light. The Journal of Physical Chemistry B 2004, 108 (19), 6004-6008.

13. Di Valentin, C.; Pacchioni, G.; Selloni, A., Origin of the different photoactivity ofN-doped anatase and rutileTiO2. Physical Review B 2004, 70 (8), 085116-4.

14. Sakthivel, S.; Kisch, H., Daylight photocatalysis by carbon-modified titanium dioxide. Angew Chem Int Ed Engl 2003, 42 (40), 4908-11.

15. Umebayashi, T.; Yamaki, T.; Yamamoto, S.; Miyashita, A.; Tanaka, S.; Sumita, T.; Asai, K., Sulfur-doping of rutile-titanium dioxide by ion implantation: Photocurrent spectroscopy and firstprinciples band calculation studies. Journal of Applied Physics 2003, 93 (9), 5156-5160.

16. Hong, X. T.; Wang, Z. P.; Cai, W. M.; Lu, F.; Zhang, J.; Yang, Y. Z.; Ma, N.; Liu, Y. J., Visiblelight-activated nanoparticle photocatalyst of iodine-doped titanium dioxide. Chemistry of Materials 2005, 17 (6), 1548-1552.

17. Huheey, J. E.; Keiter, E. A.; Keiter, R. L., Inorganic Chemistry: Principles of Structure and Reactivity. 4 ed.; Harper Collins College Publishers: 1993.

18. Teoh, W. Y.; Amal, R.; Madler, L.; Pratsinis, S. E., Flame sprayed visible light-active Fe-TiO2 for photomineralisation of oxalic acid. Catalysis Today 2007, 120 (2), 203-213.

19. Yu, J. G.; Yu, H. G.; Ao, C. H.; Lee, S. C.; Yu, J. C.; Ho, W. K., Preparation, characterization and photocatalytic activity of in situ Fe-doped TiO2 thin films. Thin Solid Films 2006, 496 (2), 273-280. 
20. Barakat, M. A.; Schaeffer, H.; Hayes, G.; Ismat-Shah, S., Photocatalytic degradation of 2chlorophenol by Co-doped TiO2 nanoparticles. Applied Catalysis B: Environmental 2005, 57 (1), 23-30.

21. Shi, J. Y.; Leng, W. H.; Zhu, W. C.; Zhang, J. Q.; Cao, C. N., Electrochemically assisted photocatalytic oxidation of nitrite over Cr-doped TiO2 under visible light. Chemical Engineering \& Technology 2006, 29 (1), 146-154.

22. Uhm, Y. R.; Woo, S. H.; Kim, W. W.; Kim, S. J.; Rhee, C. K., The characterization of magnetic and photo-catalytic properties of nanocrystalline Ni-doped $\mathrm{TiO} 2$ powder synthesized by mechanical alloying. Journal of Magnetism and Magnetic Materials 2006, 304 (2), e781-e783.

23. Anpo, M.; Takeuchi, M.; Ikeue, K.; Dohshi, S., Design and development of titanium oxide photocatalysts operating under visible and UV light irradiation. The applications of metal ionimplantation techniques to semiconducting TiO2 and Ti/zeolite catalysts. Curr Opin Solid St M 2002, 6 (5), 381-388.

24. Choi, J.; Park, H.; Hoffmann, M. R., Effects of Single Metal-Ion Doping on the Visible-Light Photoreactivity of TiO2. J Phys Chem C 2010, 114 (2), 783-792.

25. Chen, C. C.; Li, X. Z.; Ma, W. H.; Zhao, J. C.; Hidaka, H.; Serpone, N., Effect of transition metal ions on the TiO2-assisted photodegradation of dyes under visible irradiation: A probe for the interfacial electron transfer process and reaction mechanism. Journal of Physical Chemistry B 2002, 106 (2), 318-324.

26. Choi, W. Y.; Termin, A.; Hoffmann, M. R., The Role of Metal-Ion Dopants in Quantum-Sized Tio2 - Correlation between Photoreactivity and Charge-Carrier Recombination Dynamics. Journal of Physical Chemistry 1994, 98 (51), 13669-13679.

27. Janisch, R.; Gopal, P.; Spaldin, N. A., Transition metal-doped TiO2 and ZnO—present status of the field. Journal of Physics: Condensed Matter 2005, 17 (27), R657-R689.

28. Matsumoto, Y.; Murakami, M.; Shono, T.; Hasegawa, T.; Fukumura, T.; Kawasaki, M.; Ahmet, P.; Chikyow, T.; Koshihara, S.; Koinuma, H., Room-temperature ferromagnetism in transparent transition metal-doped titanium dioxide. Science 2001, 291 (5505), 854-6.

29. Bryan, J. D.; Santangelo, S. A.; Keveren, S. C.; Gamelin, D. R., Activation of high-TC ferromagnetism in $\mathrm{Co} 2+: \mathrm{TiO} 2$ and $\mathrm{Cr} 3+: \mathrm{TiO} 2$ nanorods and nanocrystals by grain boundary defects. J Am Chem Soc 2005, 127 (44), 15568-74.

30. Zhang, W.; Zhou, W.; Wright, J. H.; Kim, Y. N.; Liu, D.; Xiao, X., Mn-doped TiO2 nanosheetbased spheres as anode materials for lithium-ion batteries with high performance at elevated temperatures. ACS Appl Mater Interfaces 2014, 6 (10), 7292-300.

31. Valero, J. M.; Obregón, S.; Colón, G., Active Site Considerations on the Photocatalytic H2Evolution Performance of Cu-Doped TiO2Obtained by Different Doping Methods. ACS Catalysis 2014, 4 (10), 3320-3329.

32. Andriamiadamanana, C.; Laberty-Robert, C.; Sougrati, M. T.; Casale, S.; Davoisne, C.; Patra, S.; Sauvage, F., Room-temperature synthesis of iron-doped anatase $\mathrm{TiO}(2)$ for lithium-ion batteries and photocatalysis. Inorg Chem 2014, 53 (19), 10129-39.

33. Wiley, J. B.; Gillan, E. G.; Kaner, R. B., Rapid Solid-State Metathesis Reactions for the Synthesis of Copper-Oxide and Other Metal-Oxides. Mater Res Bull 1993, 28 (9), 893-900.

34. Gillan, E. G.; Kaner, R. B., Synthesis of refractory ceramics via rapid metathesis reactions between solid-state precursors. Chemistry of Materials 1996, 8 (2), 333-343.

35. Parkin, I. P., Solid state metathesis reaction for metal borides, silicides, pnictides and chalcogenides: Ionic or elemental pathways. Chemical Society Reviews 1996, 25 (3), 199-+.

36. Bonneau, P. R.; Jarvis, R. F.; Kaner, R. B., Rapid Solid-State Synthesis of Materials from Molybdenum-Disulfide to Refractories. Nature 1991, 349 (6309), 510-512.

37. Treece, R. E.; Macala, G. S.; Kaner, R. B., Rapid synthesis of gallium phosphide and gallium arsenide from solid-state precursors. Chemistry of Materials 1992, 4 (1), 9-11. 
38. Cumberland, R. W.; Blair, R. G.; Wallace, C. H.; Reynolds, T. K.; Kaner, R. B., Thermal control of metathesis reactions producing GaN and InN. Journal of Physical Chemistry B 2001, 105 (47), 11922-11927.

39. Gillan, E. G.; Kaner, R. B., Rapid Solid-State Synthesis of Refractory Nitrides. Inorganic Chemistry 1994, 33 (25), 5693-5700.

40. Fitzmaurice, J. C.; Hector, A. L.; Parkin, I. P., Low-temperature routes to early transition-metal nitrides. Journal of the Chemical Society, Dalton Transactions 1993, (16), 2435-2438.

41. Hector, A. L.; Parkin, I. P., Sodium azide as a reagent for solid state metathesis preparations of refractory metal nitrides. Polyhedron 1995, 14 (7), 913-917.

42. Hector, A. L.; Parkin, I. P., Self-propagating routes to transition-metal phosphides. Journal of Materials Chemistry 1994, 4 (2), 279-283.

43. Hector, A. L.; Parkin, I. P., Solid-State Metathesis Preparations of Group-Viii Metal-Oxide Powders. Journal of Materials Science Letters 1994, 13 (3), 219-221.

44. Aguas, M. D.; Coombe, G. C.; Parkin, I. P., New solid state routes to lithium transition metal oxides via reactions with lithium oxide. Polyhedron 1998, 17 (1), 49-53.

45. Parkin, I. P.; Komarov, A. V.; Fang, Q., Alternative solid state routes to mixed metal oxides (LnCrO(3), LnFeO(3)). Polyhedron 1996, 15 (18), 3117-3121.

46. Gillan, E. G.; Kaner, R. B., Rapid, energetic metathesis routes to crystalline metastable phases of zirconium and hafnium dioxide. Journal of Materials Chemistry 2001, 11 (7), 1951-1956.

47. Perera, S.; Zelenski, N.; Gillan, E. G., Synthesis of Nanocrystalline TiO2and Reduced Titanium Oxides via Rapid and Exothermic Metathesis Reactions. Chemistry of Materials 2006, 18 (9), 2381-2388.

48. Perera, S.; Gillan, E. G., A facile solvothermal route to photocatalytically active nanocrystalline anatase TiO2 from peroxide precursors. Solid State Sciences 2008, 10 (7), 864-872.

49. Carver, J. C.; Carlson, T. A.; Schweitz.Gk, Use of X-Ray Photoelectron Spectroscopy to Study Bonding in Cr, Mn, Fe, and Co Compounds. J Chem Phys 1972, 57 (2), 973-\&.

50. Allen, G. C.; Curtis, M. T.; Hooper, A. J.; Tucker, P. M., X-Ray Photoelectron Spectroscopy of Chromium-Oxygen Systems. J Chem Soc Dalton 1973, (16), 1675-1683.

51. Di Castro, V.; Polzonetti, G.; Contini, G.; Cozza, C.; Paponetti, B., XPS study of MnO2 minerals treated by bioleaching. Surface and Interface Analysis 1990, 16 (1-12), 571-574.

52. Umezawa, Y.; Reilley, C. N., Effect of Argon Ion-Bombardment on Metal-Complexes and Oxides Studied by X-Ray Photoelectron-Spectroscopy. Anal Chem 1978, 50 (9), 1290-1295.

53. Chuang, T. J.; Brundle, C. R.; Rice, D. W., Interpretation of the X-ray photoemission spectra of cobalt oxides and cobalt oxide surfaces. Surface Science 1976, 59 (2), 413-429.

54. Khawaja, E. E.; Salim, M. A.; Khan, M. A.; Aladel, F. F.; Khattak, G. D.; Hussain, Z., Xps, Auger, Electrical and Optical Studies of Vanadium Phosphate-Glasses Doped with Nickel-Oxide. J Non-Cryst Solids 1989, 110 (1), 33-43.

55. Wanger, C. D., Riggs, W. M., Davis, L. E., Moulder, J. F., Muilenberg, G. E., Handbook of X-ray Photoelectron Spectroscopy. Perkin Elmer Corporation: Eden Prairie, MN, 1979. 